\title{
Study of Hydrogen Internal Combustion Engine Vehicles Based on the Whole Life Cycle Evaluation Method
}

\author{
Ping Guo, Jianlun Xu, Chuanhao Zhao and Baoliang Zhang \\ School of Mechanical Engineering, North China University of Water Resources and Electric Power, \\ Zhengzhou, Henan 450045, China
}

Received January 1, 2022; Accepted January 22, 2022; Published February 2, 2022

\begin{abstract}
In order to better achieve the goal of low carbon emissions from vehicles, a whole life cycle assessment of hydrogen-fueled internal combustion engine vehicles has been conducted in recent years. Based on the study of hydrogen use around the world, we studied the emission and economic performance of hydrogen-fueled internal combustion engine vehicles from the beginning of hydrogen production to the end of use (Well-to-Wheel, WTW) based on the whole life cycle evaluation method. The results show that the overall environmental impact of hydrogen production by steam reforming of natural gas is the smallest, and that the rational use of "abandoned electricity" for hydrogen production from electrolytic water in the western part of China significantly reduces the overall environmental impact and the cost of hydrogen production. In the use phase, the emissions are less, which not only can meet the National 6 emission standard, but also can reach higher emission standard after adding exhaust gas recirculation (EGR). From the whole life cycle point of view, hydrogen-fueled internal combustion engine has a very good development prospect.
\end{abstract}

Keywords: Whole Life Cycle; Hydrogen Fuel Internal Combustion Engine; Emission; Economy

\section{Introduction}

By 2020, the number of cars in China has reached 281 million [1], which results in the problem of pollutant emissions and energy consumption. According to 2020 data, China's dependence on imported oil has reached $69.84 \%$ in 2020 [2]. Hydrogen, as a clean and renewable new energy source, can not only reduce the emission of pollutants from vehicles, but also alleviate the problem of transitional dependence on traditional energy sources.

In this study, a comprehensive evaluation of new energy vehicles fueled by hydrogen is conducted from the whole life cycle of the energy source. Most studies on the whole life cycle evaluation of hydrogen have focused on hydrogen fuel cell vehicles. Lin et al. [3] used the GREET model to comprehensively evaluate the $\mathrm{CO}_{2}$ emissions of hydrogen fuel cell vehicles under various routes of hydrogen fuel production and concluded that the energy consumption and $\mathrm{CO}_{2}$ emissions could be reduced by $90 \%$ under the clean way of hydrogen production. Chen [4], Andrew [5], and Kong et al. [6] studied the emissions during the production of different hydrogen production methods, and obtained the most economical and least emitting method through comparative analysis. Changing the power generation structure not only reduces the overall

*Corresponding author: Ping Guo (1999-), female (Han nationality), master's degree student, the main research direction is the combustion and optimization of clean energy vehicle engines. E-mail: 
environmental impact value of electrolytic water hydrogen production, but also reduces the cost of hydrogen production. Daniele et al. [7] evaluated the life-cycle performance of three different types of vehicles based on wind power electrolysis of water for hydrogen production and the results showed that hydrogen fuel is an excellent decarbonization solution. Both Dong et al. [8] and Huang et al. [9] performed life cycle analysis of the environmental impact of fuel cell vehicle energy under different fossil fuel-based hydrogen fuel paths. The results showed that supplying fuel cell vehicles with hydrogen from natural gas reforming is the most advantageous in terms of energy saving and emission reduction.

Hydrogen-fueled internal combustion engines are another way to use hydrogen as an alternative energy source. Hydrogen fuel cells are hampered by materials and technology, which provides an opportunity for the development of hydrogen-fueled internal combustion engines. The use of hydrogen fuel cells involves electrochemical reactions which require the purity of the hydrogen used (usually greater than $99.99 \%$ ) to minimize the impact of impurities in the hydrogen on the catalyst and electrolyte, while hydrogen-fueled internal combustion engines require low purity of hydrogen. In contrast, hydrogen internal combustion engines have a definite advantage in terms of manufacturing and fuel purification costs. There are no reports on the life cycle of hydrogen-fueled internal combustion engine vehicles in China, and few studies have been done by other countries. Halim et al. [10] compared gasoline doped hydrogen with pure gasoline engine and analyzed the investment cost planning of two different combustion modes in five and ten years, and the results showed that after the fourth year, the investment cost of gasoline doped hydrogen car is lower than that of pure gasoline car, and the gap increases gradually with the increase of service life. However, the main study focuses on the consumption in the hydrogen production phase, and does not analyze the emissions and energy consumption in the combustion phase, which is not a comprehensive evaluation. In summary, the study of the whole life cycle of hydrogen fueled internal combustion engines not only reveals the application prospects of hydrogen fueled internal combustion engines, but also makes the evaluation of hydrogen fuel in vehicles more comprehensive.

\section{Research Methods and Contents}

\section{Whole Life Cycle Evaluation Method}

Life cycle evaluation method is a method of aggregating and evaluating one or more specific indicators of a product (service) system throughout its life cycle in terms of all inputs, outputs, and their direct or indirect impacts on the external environment [11]. The life cycle assessment of vehicles can be described as a well-to-wheel (WTW) process, which can be divided into two stages: well-to-tank (WTT) and tank-to-wheel (TTW). The hydrogen-fueled internal combustion engine can be described as the stages of hydrogen production, transportation, and use of hydrogen fuel in the internal combustion engine. The system boundary is shown in Figure 1. 


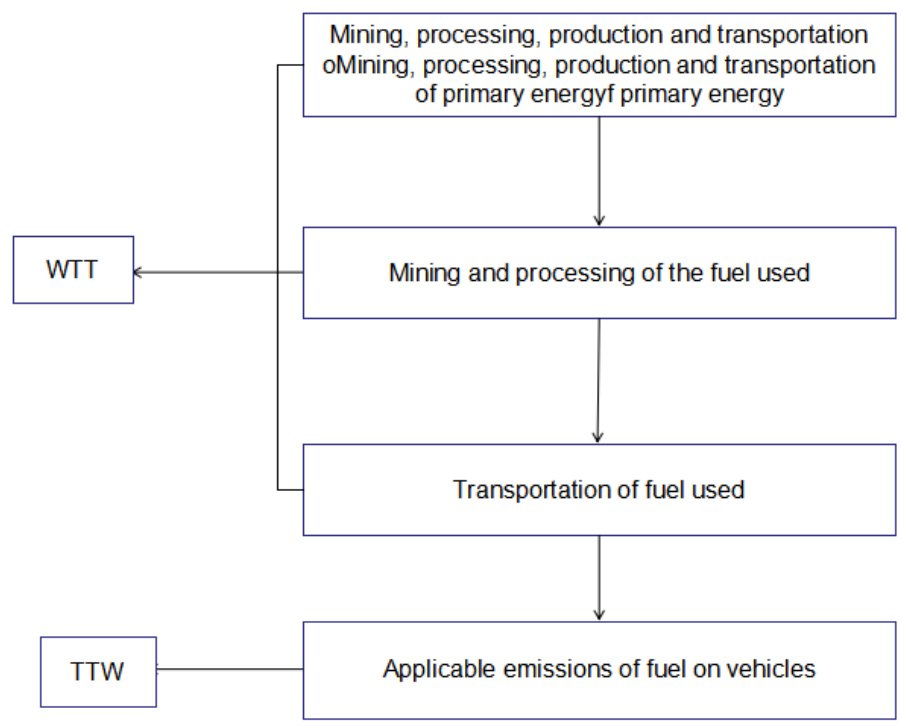

Figure 1. Hydrogen fuel system boundary

\section{Research Content}

This study focuses on the whole life cycle analysis of a hydrogen-fueled internal combustion engine by selecting the two most and least energy-consuming and emissionconsuming ways to produce hydrogen from a variety of hydrogen production methods, and considering the whole life cycle of hydrogen from the generation of hydrogen to the end of its emission after use in a hydrogen-fueled internal combustion engine, focusing on the production, manufacturing, and use costs (i.e., understood the economics) and the emission of pollutants (mainly $\mathrm{NO}_{\mathrm{x}}$ and $\mathrm{CO}_{2}$-based emissions). Because only a simple modification of a conventional gasoline engine is needed to burn hydrogen and the weight of the vehicle manufacturing process itself is less than $1 \%$ [12], in order to study the main content, the vehicle manufacturing process is ignored and only the energy consumption and pollutant emissions during the production and manufacturing costs of hydrogen fuel and its use in the vehicle are focused.

\section{Two-stage Energy Consumption and Emissions}

\section{Hydrogen Production Method}

1. Hydrogen production by steam reforming of natural gas: The basic principle of producing hydrogen from natural gas is to use natural gas, high-temperature steam and synthetic reaction to form a mixture of hydrogen $\left(\mathrm{H}_{2}\right)$, carbon monoxide $(\mathrm{CO})$ and a small amount of carbon dioxide $\left(\mathrm{CO}_{2}\right)$. $\mathrm{CO}$ reacts with water again to produce additional hydrogen. Hydrogen production by steam reforming of natural gas is the most effective and common hydrogen production technology. The chemical reaction formula are as follows:

Conversion reaction: $\mathrm{CH}_{4}+\mathrm{H}_{2} \mathrm{O}=\mathrm{CO}+3 \mathrm{H}_{2}$

Transformation reaction: $\mathrm{CO}+\mathrm{H}_{2} \mathrm{O}=\mathrm{CO}_{2}+\mathrm{H}_{2}$

Total reaction: $\mathrm{CH}_{4}+2 \mathrm{H}_{2} \mathrm{O}=\mathrm{CO}_{2}+4 \mathrm{H}_{2}$

2. Hydrogen production by water electrolysis: The principle of hydrogen production by water electrolysis is electrochemical reaction which uses direct current to 
electrolyze the electrolyte, and chemical reactions that occur at the two ends of different electrodes, thereby producing hydrogen and oxygen at the cathode and anode, respectively. The chemical reaction formula is as follows:

Cathodic reaction: $4 \mathrm{e}-+4 \mathrm{H}_{2} \mathrm{O}=2 \mathrm{H}_{2} \uparrow+4 \mathrm{OH}-$

Anode reaction: $4 \mathrm{OH}-=2 \mathrm{H}_{2} \mathrm{O}+\mathrm{O}_{2} \uparrow+4 \mathrm{e}-$

The total reaction formula is: $2 \mathrm{H}_{2} \mathrm{O}=2 \mathrm{H}_{2} \uparrow+\mathrm{O}_{2} \uparrow$

3. Coke oven gas hydrogen production method: Coke oven gas is a hydrogen-rich combustible gas. Using coke oven gas after removing impurities, the pressure swing adsorption separation method can be used to produce hydrogen.

In order to study the value of the entire hydrogen energy production range, this research selects hydrogen production by steam reforming of natural gas and electrolysis water hydrogen production methods for research.

\section{Energy Consumption and Emissions in WTT Phase}

Energy Consumption for Hydrogen Production

The consumption of one cubic meter of hydrogen produced under standard conditions (the quantities of reactants and products involved in the following are standard conditions) is analyzed. The cost of hydrogen production mainly includes natural gas costs, deionized water costs, cooling water costs, and electricity costs. For the four parts, the prices of raw materials are based on the relevant standards and related documents [1314] announced by Beijing in 2021:

Table 1. Consumption and unit price of raw materials for producing 1 cubic meter of hydrogen (Unit : Yuan $¥$ )

\begin{tabular}{cccc}
\hline & $\begin{array}{c}\text { Natural gas steam } \\
\text { Reforming hydrogen } \\
\text { production }\end{array}$ & $\begin{array}{c}\text { Electrolyte } \\
\text { Hydrogen production }\end{array}$ & Unit price \\
\hline Natural gas $/ \mathrm{m}^{3}$ & 0.48 & 0.00 & 4.25 \\
Deionized water $/ \mathrm{kg}$ & 1.30 & 0.88 & 0.069 \\
Cooling water $/ \mathrm{kg}$ & 6.00 & 3.00 & 0.003 \\
Electricity $/$ degree & 0.40 & 5.50 & 0.25 \\
Equipment depreciation & 0.1583 & 0.1286 & - \\
\hline
\end{tabular}

Based on the data in Table 1, the costs for producing 1 cubic meter of hydrogen via steam reforming of natural gas and electrolysis of water are 2.37604 and 2.14474 yuan, respectively. From the perspective of production costs, the cost of hydrogen production from electrolysis of water is lower, which is $9.61 \%$ lower than that of natural gas reforming.

\section{Hydrogen Production Emissions}

(1) Emissions from hydrogen production by steam reforming of natural gas

Natural gas is a primary energy source. The main components are methane and a small amount of olefins. There is no harmful gas emission during the acquisition process, but $\mathrm{CO}_{2}$ is emitted during the hydrogen production process.

(2) Discharge of hydrogen production by electrolysis of water

There will be no emissions of pollutants in the process of electrolysis of water to produce hydrogen. But if considering that thermal power generation accounts for $73.32 \%$ 
of the total power generation of china, pollutants are emitted during the power generation process.

Comparison of Two Hydrogen Production Schemes

Table 2. Energy consumption and emissions of the two hydrogen production schemes

\begin{tabular}{ccc}
\hline & Natural gas reforming to produce hydrogen & Hydrogen production by electrolysis of water \\
\hline $\mathrm{Coal} / \mathrm{kg}$ & 0.000 & 0.320 \\
$\mathrm{CH}_{4} / \mathrm{m}^{3}$ & 0.480 & 0.000 \\
$\mathrm{CO} / \mathrm{kg}$ & 0.005 & 0.136 \\
$\mathrm{CO}_{2} / \mathrm{kg}$ & 0.491 & 1.030 \\
$\mathrm{NOx} / \mathrm{kg}$ & 0.007 & 0.015 \\
$\mathrm{SO}_{2} / \mathrm{kg}$ & 0.007 & 0.030 \\
$\mathrm{PM} 2.5 / \mathrm{kg}$ & 0.001 & 0.081 \\
\hline
\end{tabular}

Table 2 shows the energy consumption and emissions of two different hydrogen production schemes to produce 1 cubic meter of hydrogen. Using CML2001 [15] to normalize and quantify the above data, the comprehensive environmental impact value is shown in Table 3:

Table 3. Comprehensive environmental impact values of the two hydrogen production schemes

\begin{tabular}{ccc}
\hline Plan & $\begin{array}{c}\text { Natural gas reforming to produce } \\
\text { hydrogen }\end{array}$ & $\begin{array}{c}\text { Hydrogen production by electrolysis } \\
\text { of water }\end{array}$ \\
\hline $\begin{array}{c}\text { Comprehensive } \\
\text { environmental impact } \\
\text { value }\end{array}$ & $4.8^{*} 10^{-11}$ & $2.99 * 10^{-9}$ \\
\hline
\end{tabular}

The comprehensive environmental impact value of hydrogen production by steam reforming of natural gas is only $1.6 \%$ of that of hydrogen production by electrolysis of water, and its impact on the environment is much smaller than that of hydrogen production by electrolysis of water, mainly because the electricity consumed comes from thermal power generation.

\section{Scenario Simulation}

The proportion of thermal power generation in western china is less than $15 \%$. Table 4 shows the power generation structure of the four western regions in China in 2020.

Table 4. Power generation structure of Sichuan, Yunnan, Tibet and Qinghai in China in 2020

\begin{tabular}{ccccc}
\hline Source & Sichuan & Yunnan & Tibet & Qinghai \\
Province & & & & \\
\hline Thermal power & $13.69 \%$ & $9.51 \%$ & $3.62 \%$ & $13.5 \%$ \\
Hydropower & $83.78 \%$ & $81.97 \%$ & $89.31 \%$ & $65.78 \%$ \\
wind power & $1.99 \%$ & $7.54 \%$ & $0.88 \%$ & $6.53 \%$ \\
Solar energy & $0.54 \%$ & $0.98 \%$ & $6.09 \%$ & $14.19 \%$ \\
total & $100 \%$ & $100 \%$ & $100 \%$ & $100 \%$ \\
\hline
\end{tabular}


For different power generation structures, the comprehensive environmental impact values of the above four places can be calculated through the GaBi model. The comprehensive environmental impact results of the electrolytic water method in different power generation structures are shown in Table 5.

Table 5. Comprehensive environmental impact value of electrolyzed water in four provinces

\begin{tabular}{ccccc}
\hline Province & Sichuan & Yunnan & Tibet & Qinghai \\
\hline $\begin{array}{c}\text { Comprehensive } \\
\text { environmental impact } \\
\text { value }\end{array}$ & $3.2 * 10^{-10}$ & $2.9 * 10^{-10}$ & $1.6 * 10^{-10}$ & $3.1 * 10^{-10}$ \\
\hline
\end{tabular}

The use of electrolyzed water to produce hydrogen in western china has less impact on the environment than the use of electrolyzed water to produce hydrogen in other cities in China. As can be seen from Tables 3 and 5, although there is still a gap compared with hydrogen production by steam reforming of natural gas, the overall environmental impact has been reduced from 62 times to 3.3 times. Since the unstable power generation of renewable energy has impacted the grid, causing grid fluctuations and insecurity, this part of the power that cannot be connected to the grid has caused a large amount of "power abandonment". Table 6 shows the statistics of china's "abandonment of electricity" in recent years.

Table 6. 2017-2020 National abandoned electricity in China

\begin{tabular}{cccc}
\hline Years Type & Abandon water & Abandon light & Abandon the wind \\
\hline 2017 & $4 \%$ & $6 \%$ & $12 \%$ \\
2018 & $5 \%$ & $3 \%$ & $7.2 \%$ \\
2019 & $4 \%$ & $2 \%$ & $4 \%$ \\
2020 & $3.39 \%$ & $2 \%$ & $3 \%$ \\
\hline
\end{tabular}

\section{Energy Consumption and Emissions in TTW Phase}

Starting from the hydrogen fuel internal combustion engine, the energy consumption and emissions of the TTW phase are analyzed. The AVL-Fire threedimensional simulation software is used for simulation. The model is based on a hydrogen-fueled internal combustion engine modified from the Jialing JH-600 singlecylinder engine. In order to ensure the reliability of the test simulation, the experimental data and the simulation data were compared at $3000 \mathrm{r} / \mathrm{min}$ and the equivalent ratio of 0.4 . The simulated value is slightly higher than the experimental value, mainly because the simulated working conditions are relatively ideal. It is believed that the cylinder is fully enclosed, and there will be some deviations in the experiment. The maximum difference is $1.2 \%$. It can be considered that this model can well reflect the actual working conditions of the hydrogen fuel internal combustion engine. 


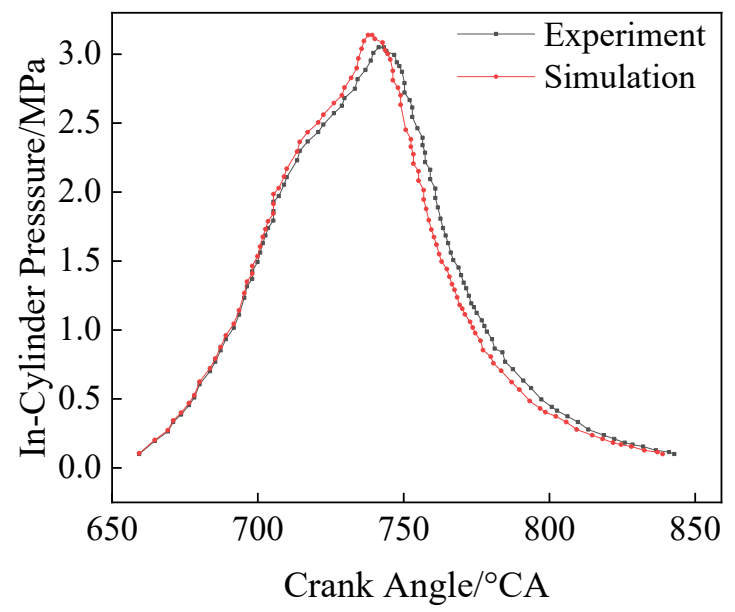

Figure 2. Model validation

\section{Energy Consumption}

Hydrogen has high thermal efficiency whether used as the power source of hydrogen fuel cell or hydrogen fuel internal combustion engine. The low calorific value of hydrogen is $119.64 \mathrm{MJ} / \mathrm{kg}$, which is 2.72 times that of gasoline. The combustion speed of hydrogen is fast, and high thermal efficiency [16]. BMW was the first company to develop hydrogen-fueled internal combustion engine vehicles. As early as 2004, BMW Motor Company conducted tests. The test result is that the hydrogen consumption per 100 kilometers is $3.7 \mathrm{~kg}$, which is equivalent to $13.8 \mathrm{~L}$ gasoline $/ 100-\mathrm{km}$. The hydrogen consumption can be reduced to $2.1 \mathrm{~kg}$ hydrogen $/ 100-\mathrm{km}$ at high speed, which is equivalent to $7.8 \mathrm{~L}$ gasoline/100-km [17]. Based on a $2.0-\mathrm{L}$ gasoline engine modified hydrogen fuel internal combustion engine test, Beijing Institute of Technology Sun Baigang and others found that when the vehicle speed reaches $80 \mathrm{~km} / \mathrm{h}$, the hydrogen consumption per 100 kilometers is $1.43 \mathrm{~kg}$. When the vehicle speed decreases, the hydrogen consumption per 100 kilometers drops to $1.27 \mathrm{~kg}$, equivalent to $4.7 \mathrm{~L}$ gasoline/100-km, which is $18.9 \%$ lower than the original engine fuel consumption [18].

Through simulation, the fuel consumption and indicated thermal efficiency of hydrogen-fueled internal combustion engines under different operating conditions are studied. Figure 3 shows that the maximum power speed of the modified hydrogen fuel internal combustion engine is $6000 \mathrm{r} / \mathrm{min}$. From the simulation results, it can be seen that at a hydrogen injection pressure of $4.5 \mathrm{bar}$, the maximum power at an equivalent ratio of 1.05 can reach $25 \mathrm{~kW}$, and the maximum hydrogen consumption is $2.124 \mathrm{~kg}$ Hydrogen $/ \mathrm{h}$ which is equivalent to $7.86 \mathrm{~L}$ gasoline/ $\mathrm{h}$. It can be seen from Figure 3 that as the engine speed increases, the indicated thermal efficiency of the hydrogen fuel internal combustion engine first increases and then decreases. The maximum indicated thermal efficiency can reach $43.2 \%$ at $3000 \mathrm{r} / \mathrm{min}$. Compared with the maximum output power of $30 \mathrm{~kW}$ of the original engine, the maximum power of the modified hydrogen fuel internal combustion engine is reduced by $16.7 \%$, but the indicated thermal efficiency can reach up to $43.2 \%$, which is a great improvement compared with the traditional gasoline engine. 


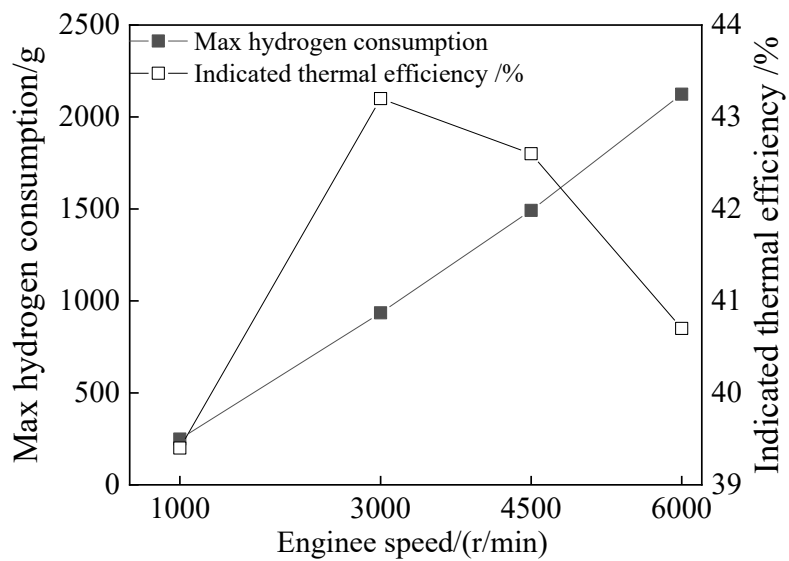

Figure 3. Maximum hydrogen consumption and indicated thermal efficiency at different speeds

\section{Emissions}

Hydrogen is a clean energy source. There are few pollutant emissions during the combustion process. Compared with traditional internal combustion engines, the emissions of unburned hydrocarbon are almost negligible. Compared with traditional internal combustion engines, the emission of greenhouse gases can be reduced by $90 \%$. The main pollutant is nitrogen oxides. In recent years, research on technologies for reducing nitrogen oxide emissions has become more and more mature, usually using exhaust gas recirculation (EGR) technology and in-cylinder water injection.

The simulation simulates the combustion emissions of the engine at 4 speeds and 5 loads. Table 7 shows the specific parameter levels:

Table 7. Simulation scheme

\begin{tabular}{|c|c|c|c|c|c|}
\hline parameter & & & leve & & \\
\hline Rotating speed rpm & 1000 & 3000 & & 4500 & 6000 \\
\hline Load & $10 \%$ & $30 \%$ & $50 \%$ & $70 \%$ & $100 \%$ \\
\hline Equivalent ratio & 0.5 & 0.6 & 0.7 & 0.84 & 1.05 \\
\hline
\end{tabular}

Table 8 shows the simulation results of nitrogen oxide emissions at different speeds and loads.

Table 8. The mass fraction of NO under different working conditions (unit: ppm)

\begin{tabular}{|c|c|c|c|c|c|}
\hline Rotational Speed & 0.5 & 0.6 & 0.7 & 0.84 & 1.05 \\
\hline $1000 \mathrm{r} / \mathrm{min}$ & 6 & 32 & 956 & 1969 & 195 \\
\hline $3000 \mathrm{r} / \mathrm{min}$ & 60 & 895 & 4064 & 4985 & 365 \\
\hline $4500 \mathrm{r} / \mathrm{min}$ & 159 & 2362 & 6256 & 6958 & 569 \\
\hline $6000 \mathrm{r} / \mathrm{min}$ & 269 & 3025 & 6589 & 7846 & 695 \\
\hline
\end{tabular}

The data in Table 8 are NO emissions under all operating conditions. When the normal working speed is below $3000 \mathrm{r} / \mathrm{min}$ and the equivalent ratio is lower than 0.5 and higher than 1.05, the NO emission is below 500ppm. At high speed and medium and high load (0.67-0.84), NO emission increases sharply. Compared with traditional internal combustion engine exhaust gas treatment devices that need to reduce $\mathrm{CO}$, unburned hydrocarbons (HC) and NO emissions, the exhaust gas treatment of hydrogen fuel internal combustion engines only needs to reduce NO emissions. The simplest technology to reduce high-load NO emissions is the EGR Technology. Table 9 shows the NO 
emission after adopting the EGR technology, in which $1000 \mathrm{r} / \mathrm{min}$ adopts 5\% EGR, and the remaining speed is $10 \%$ EGR.

By comparing Table 8 and Table 9, it can be found that the highest reduction in NO emissions after the use of EGR technology has reached 94.1\%. At $1000 \mathrm{r} / \mathrm{min}$ and $3000 \mathrm{r} / \mathrm{min}$ speeds, it is lower than $50 \mathrm{ppm}$ at full load and low load, which is close to zero emission. The main reasons for the reduction of $\mathrm{NO}$ emissions are: increasing EGR reduces the fresh charge in the combustible mixture, the maximum combustion temperature in the cylinder decreases, the high temperature duration decreases, and the optimal NO generation conditions are changed. $4500 \mathrm{r} / \mathrm{min}$ and $6000 \mathrm{r} / \mathrm{min}$ are the highest torque speed and the highest power speed. The NO emission is higher under medium and high loads, but the frequency of use is low. If you need to work at this speed for a short time, you can appropriately sacrifice the output power and the use of $15 \%$ EGR can reduce NO emissions by $92.6 \%$, and it is also less than $500 \mathrm{ppm}$ under medium and high loads.

Table 9. NO emissions (ppm) under different working conditions after using EGR

\begin{tabular}{lccccc}
\hline $\begin{array}{l}\text { Rotational } \\
\text { Speed }\end{array}$ & 0.5 & 0.6 & 0.7 & 0.84 & 1.05 \\
\hline & & & & & 11.7 \\
& 0.4 & 1.9 & 58.7 & 210.3 & 21.9 \\
$3000 \mathrm{r} / \mathrm{min}$ & 3.5 & 53.7 & 243.6 & 485.6 & 142.2 \\
$4500 \mathrm{r} / \mathrm{min}$ & 39.8 & 590.5 & 1564 & 1739.5 & 173.8 \\
$6000 \mathrm{r} / \mathrm{min}$ & 67.2 & 756.3 & 1647.3 & 1961.5 & \\
\hline
\end{tabular}

Table 10. Emission test of hydrogen fuel internal combustion engine

\begin{tabular}{cccc}
\hline Projects & \multicolumn{2}{c}{ Emissions $/(\mathrm{g} / \mathrm{km})$} & NOx \\
\hline CHINA 6 & 0.7 & HC & 0.05 \\
Simulation results & 0.09 & 0.068 & 0.042 \\
\hline
\end{tabular}

Table 10 shows the various emissions after increasing EGR. According to limits and measurement methods for emissions from light-duty vehicles (CHINA 6). Carbon monoxide emissions are only $12.8 \%$ of the regulations, $\mathrm{HC}$ emissions are $48.5 \%$ of the regulations, and nitrogen oxides emissions are slightly higher, at $84 \%$ of the regulations.

In addition to adding exhaust gas treatment equipment, there are many ways to reduce nitrogen oxides. (1) Hydrogen has a wide range of flammable limits, and controlling the equivalent ratio below 0.5 or above 1.05 can effectively reduce NO emissions; (2) It is possible to mix hydrogen and natural gas to reduce nitrogen oxides at the expense of low carbon emissions Emissions.

\section{CONCLUSIONS}

(1) The comprehensive environmental impact of hydrogen production by steam reforming of natural gas is only $1.6 \%$ of that of hydrogen production from electrolyzed water; in western china, "abandonment of electricity" is used to produce hydrogen from electrolyzed water, and the cost of hydrogen production from electrolyzed water is only $1 / 10$ of that from natural gas reforming. 
(2) The hydrogen consumption per hundred kilometers of the modified hydrogen internal combustion engine is $12.3 \%$ lower than the fuel consumption of the original gasoline engine without modification.

(3) The $\mathrm{NO}_{\mathrm{x}}$ emission of hydrogen fuel internal combustion engine is greatly reduced under the working conditions of equivalent ratio less than 0.5 and higher than 1.05. Under the coordination of EGR technology under medium and high loads, it can easily reach the national VI emission standards and there is room for further improvement.

\section{Conflict of Interest}

The authors declare that there is no conflict of interests regarding the publication of this paper.

\section{ACKNOWLEDGMENTS}

This research was supported by Special support plan for high-level talents of Henan Province- "ZHONGYUAN Thousand Talent Program” (ZYQR201810075).

\section{REFERENCES}

[1] Jiang, C., Wang, X., and Wang, Z. (2021). Research on automobile sales forecasting methods based on consumer attention. Data Analysis and Knowledge Discovery, 5(1), 128-139

[2] Liu, C., and Jiang, X. (2019). The overall recovery of the oil and gas order reconstruction industry-an overview of the development of the domestic and foreign oil and gas industry in 2018 and the outlook for 2019. International Petroleum Economics, 27(1), 27-33+60

[3] Lin, T., Wu, Ye., He, X., Zhang, S., and Hao, J. (2018). Fossil energy consumption and $\mathrm{CO}_{2}$ emissions during the fuel life cycle of hydrogen fuel cell vehicles in China. Environmental Science, 39(8), 3946-3953

[4] Chen, Y., Ding, Z., Wang, W., and Liu, J. (2019). Full life cycle assessment and scenario simulation of different hydrogen production schemes for hydrogen fuel cell vehicles. Chinese Journal of Highways, 32(5), 172-180

[5] Simons, A., and Bauer, C. (2015). A life-cycle perspective on automotive fuel cells. Applied Energy, 157, 884-896. DOI: https://doi.org/10.1016/j.apenergy.2015.02.049

[6] Kong, D., Tang, W., Liu, W., and Wang, M. (2018). Energy consumption, emission and economic evaluation of fuel cell vehicles. Journal of Tongji University (Natural Science Edition), 46(4), 498-503+523

[7] Candelaresi, D., Valente, A., Iribarren, D., Dufour, J., and Spazzafumo, G. (2021). Comparative life cycle assessment of hydrogen-fuelled passenger cars. International Journal of Hydrogen Energy, 46(72), 35961-35973. DOI: https://doi.org/10.1016/j.ijhydene.2021.01.034 
[8] Dong, J., Liu, X., Xu, X., and Zhang, S. (2016). Comparative life cycle assessment of hydrogen pathways from fossil sources in China. International Journal of Energy Research, 40(15), 2105-2116. DOI: https://doi.org/10.1002/er.3586

[9] Huang, Z., and Zhang, X. (2006). Well-to-wheels analysis of hydrogen based fuel-cell vehicle pathways in Shanghai. Energy, 31(4), 471-489. DOI:

https://doi.org/10.1016/j.energy.2005.02.019

DOI:10.1016/j.energy.2005.02.019.DOI:10.1016/j.energy.2005.02.019.

[10] Razali, H., Sopian, K., and Mat, A. S. (2013). Hydrogen as an Alternative: Life Cycle Cost Analysis between Hydrogen Internal Combustion Engine (Al+Hci) and Gasoline Engine Based on Brake Specific Fuel Consumption. Applied Mechanics and Materials, 315, 423-427. DOI:

10.4028/www.scientific.net/AMM.315.423

[11] Xie, X., Yang, W., Shi, W., Zhang, S., Wang, Z., and Zhou, J. (2018). Research progress in life cycle assessment of hydrogen production technology. Progress in Chemical Industry, 37(6), 2147-2158

[12] Meng, X., Wen, H., Zeng, A., and Shao, Y. (2020). Post-war material recovery vehicle path optimization based on improved ACO. Firepower and Command Control, 45(9), 47-51

[13] Zhang, X., Wei, X., Han, J., Chou, Q., and Chen, J. (2010). Talk about the use of deionized water in hydrogen production by water electrolysis. Science and Technology Information, 25, 86

[14] Guo, X., Huang, X., Zhang, K., Han, G., and Han, P. (2020). Research on the development status and price of natural gas power generation in China. Zhejiang Electric Power, 39(9), 109-117

[15] Chen, Y., Yang, Y., Li, X., Dong, H., and Bai, R. (2014). Life cycle resource consumption of automotive power seats. International Journal of Environmental Studies, 71(4), 449-462

[16] Fu, H., Chai, H., Sun, B., and Bao, L. (2020). Effects of Oxygen-Enriched Combustion on Performance of PFI Hydrogen Engine. Vehicle Engine, 2020(4), 1-6. DOI: 10.3969/j.issn.1001-2222.2020.04.001

[17] Wallner, T., Lohse-Busch, H., Gurski, S., Duoba, M., Thiel, W., Martin, D., and Korn, T. (2008). Fuel economy and emissions evaluation of BMW Hydrogen 7 Mono-Fuel demonstration vehicles. International Journal of Hydrogen Energy, 33(24), 7607-7618. DOI: https://doi.org/10.1016/j.ijhydene.2008.08.067

[18] Sun, B., Xiang, Q., and Liu, F. (2012). Hydrogen fuel internal combustion engine and vehicle performance test research. Journal of Beijing Institute of Technology, 32(10): 1026-1030

Article copyright: (C) 2022 Ping Guo, Jianlun Xu, Chuanhao Zhao and Baoliang Zhang. This is an open access article distributed under the terms of the Creative Commons Attribution 4.0 International License, which permits unrestricted use and distribution provided the original author and source are credited. 